\title{
PENGARUH GAYA KEPEMIMPINAN, LINGKUNGAN KERJA \& KOMPENSASI TERHADAP MOTIVASI KERJA PEGAWAI PENYANDANG DISABILITAS GALERI BATIK WISTARA SURABAYA
}

\author{
Arie Dwi Kurniawan ${ }^{1}$, Widhayani Puri Setioningtyas² \\ Universitas PGRI Adi Buana Surabaya1,2 \\ ariedk2173@gmail.com
}

\begin{abstract}
ABSTRAK
Dalam meningkatkan motivasi kerja pegawai disabilitas dapat dipengaruhi dari berbagai faktor seperti gaya kemepimpinan yang baik dan pemberian kompensasi yang adil. Penelitian ini bertujuan untuk mengetahui dan menganalisis pengaruh pengaruh gaya kepemimpinan, lingkungan kerja, dan kompensasi terhadap motivasi kerja pegawai penyandang disabilitas di Galeri Batik Wistara Surabaya. Populasi dalam penelitian ini sebanyak 22 pegawai dan seluruh jumlah populasi dijadikan sampel dengan menggunakan metode sampel total atau yang biasa disebut sensus. Penelitian ini menggunakan metode penelitian kuantitatif dengan menggunakan analisis regresi linier berganda dengan menggunakan batuan softwere SPSS versi 24. Secara parsial gaya kepemimpinan berpengaruh signifikan terhadap motivasi kerja, lingkungan kerja berpengaruh signifikan terhadap motivasi kerja, sedangkan kompensasi tidak berpengaruh signifikan terhadap motivasi kerja pegawai penyandang disabilitas di Galeri Batik Wistara Surabaya.
\end{abstract}

Kata kunci: Gaya Kepemimpinan, Lingkungan Kerja, Kompensasi, Motivasi Kerja.

\begin{abstract}
In increasing the work motivation of employees with disabilities can be influenced by various factors such as good leadership style, supportive working environment, and fair compensation. This study aims to determine and analyze the influence of the influence of leadership style, work environment, and compensation to the work motivation of employees with disabilities at the Batik Wistara Gallery in Surabaya. The population in this study were 22 employees and the entire population was sampled using the total sample method or commonly called the census. This study uses quantitative research methods using multiple linear regression analysis using SPSS version 24. The leadership style partially has a significant effect on work motivation, the work environment has a significant effect on work motivation, while compensation has no significant effect on the work motivation of employees with disabilities in Wistara Batik Gallery, Surabaya.
\end{abstract}

Keywords: Leadership Style, Work Environment, Compensation, Work Motivation. 


\section{PENDAHULUAN \\ Latar Belakang}

Pada dasarnya manusia dilahirkan di dunia dengan kelebihan serta kekurangan berbeda satu sama lain, Secara fisik, manusia dibedakan menjadi dua golongan yakni manusia dengan fisik yang normal dan manusia dengan fisik yang tidak normal (disabilitas). Manusia dengan fisik yang normal yaitu manusia yang dapat beraktivitas tanpa kendala di fisiknya. Sedangkan manusia dengan fisik yang tidak normal biasanya dikenal dengan istilah penyandang disabilitas (cacat), artinya manusia yang anggota tubuhnya tidak dapat digunakan sesuai dengan fungsi yang sebagaimana mestinya. Contohnya antara lain: tuna daksa, tuna netra, tuna rungu, penyandang disabilitas mental, serta kronis. Manusia dengan kekurangan fisik sangatlah rentan akan diskriminasi sosial dari masyarakat, anggapan tentang tidak dibutuhkannya manusia cacat akan berbegai pekerjaan sudah umum kita dengar. Akan tetapi manusia diciptakan punya keistimewaan tersendiri, kita sebagai manusia normal sewajarnya untuk terus menyusukuri nikmat ini yang tak terhingga.

Efendi dan Rahaditya (2017:97) menyatakan bahwa penyandang disabilitas dilihat dari tingginya jumlah penyandang disabilitas membuat sangat sulitnya dalam memasuki akses di dunia kerja dikarenakan berbadai macam hambatan, sehingga menyebabkan banyaknya jumlah pengangguran bagi para penyandang disabilitas. Penyandang disabilitas juga cenderung memperoleh persepsi negatif dalam masalah keterbatasan, ketidakmampuan, dan ketidakberdayaan.

Sebagai manusia dengan segala bentuk kekrungan serta kelebihan satu sama lainnya, hendaknya selalu menaruh sikap merata kepada sesama manusia. Pentingnya peran perusahaan dalam menciptakan motivasi agar pegawai penyandang disabiltas untuk terus percaya diri mengembangkan skill tanpa harus merendahkan.

\section{Rumusan Masalah}

Dijelaskan masalah sebagai berikut:

1. Adakah gaya kepemimpinan berpengaruh terhadap motivasi kerja pegawai penyandang disabilitas Galeri Batik Wistara Surabaya?

2. Adakah lingkungan kerja berpengaruh terhadap motivasi kerja pegawai penyandang disabilitas Galeri Batik Wistara Surabaya?

3. Adakah kompensasi berpengaruh terhadap motivasi kerja pegawai Penyandang Disabilitas Galeri Batik Wistara Surabaya?

\section{Kerangka Konseptual}

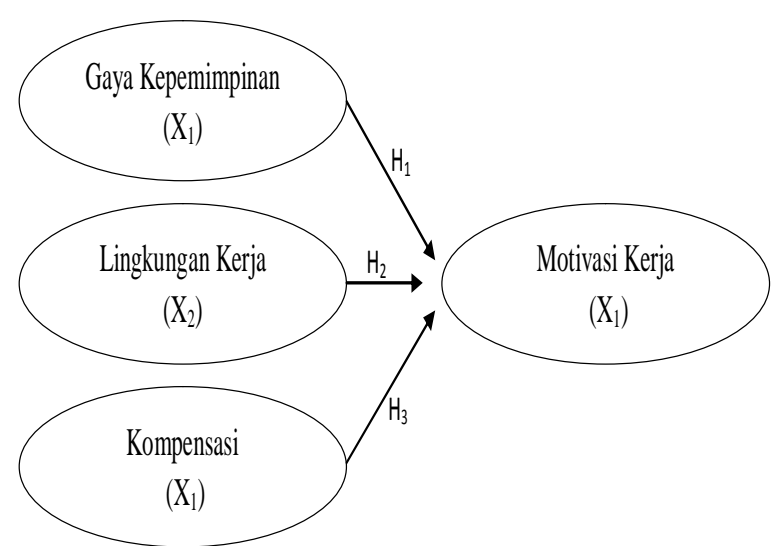

Gambar 1. Kerangka Konseptual Penelitian 


\section{METODE}

Dijelaskan penelitian memakai pendekatan kuantitatif deskriptif, adapun sampel yakni pegawai penyandang disabilitas Galeri Batik Wistara Surabaya. Sampel penelitian sebanyak 22 pegawai. Metode penelitian memakai sensus atau istilah sampel total. Tempat penelitian dilakukan pada Galeri Batik Wistara Surabaya.

HASIL

Intrumen Penelitian

Tabel 1. Uji Validitas dan Uji Reliabilitas

Validitas

\begin{tabular}{|c|c|c|c|c|c|c|}
\hline \multicolumn{5}{|c|}{ Validitas } & \multicolumn{2}{|c|}{ Reabilitas } \\
\hline Variabel & $\begin{array}{c}\text { Item } \\
\text { Portanyaan }\end{array}$ & $r$ hituri & Sig. & Koterangan & $\begin{array}{l}\text { Cronbech's } \\
\text { Alphe }\end{array}$ & Koterangan \\
\hline \multirow{12}{*}{$\begin{array}{l}\text { Gaya Kepemimpinan } \\
\qquad\left(x_{1}\right)\end{array}$} & $\times 1.1 .1$ & $.732^{*}$ & 0,000 & Valid & \multirow{12}{*}{0.920} & \multirow{12}{*}{ Reliabel } \\
\hline & $\times 1.1 .2$ & $695^{*}$ & 0,000 & Valid & & \\
\hline & $\times 1.2 .1$ & $.738^{\circ}$ & 0.000 & Valid & & \\
\hline & $\times 1.2 .2$ & $.715^{\circ}$ & 0,000 & Valid & & \\
\hline & $\times 1.3 .1$ & $.764^{-1}$ & 0,000 & Vatid & & \\
\hline & $\times 1,3.2$ & $.736^{\circ}$ & 0.000 & Valid & & \\
\hline & $\times 1.4 .1$ & $.755^{\circ}$ & 0.000 & Valid & & \\
\hline & $\times 1.4 .2$ & $.743^{*}$ & 0.000 & Valid & & \\
\hline & $\times 1.5 .1$ & $.777^{*}$ & 0,000 & Valid & & \\
\hline & $\times 1.5 .2$ & $.661^{\circ}$ & 0,001 & Valid & & \\
\hline & $\times 1.6 .1$ & $.734^{-}$ & 0,000 & Valid & & \\
\hline & $\times 1.6 .2$ & $699^{-1}$ & 0,000 & Valid & & \\
\hline \multirow{12}{*}{$\begin{array}{l}\text { Lingkungan Kerja } \\
\qquad\left(x_{2}\right)\end{array}$} & $\times 2.1 .1$ & $.724^{*}$ & 0.000 & Valid & \multirow{12}{*}{0.931} & \multirow{12}{*}{ Reliabel } \\
\hline & $\times 2.1 .2$ & $755^{-1}$ & 0,000 & Valid & & \\
\hline & $\times 2.2 .1$ & $.719^{-1}$ & 0.000 & Valid & & \\
\hline & $\times 2.2 .2$ & $.785^{\circ}$ & 0.000 & Valid & & \\
\hline & $\times 2.3 .1$ & $.762^{*}$ & 0.000 & Valid & & \\
\hline & $\times 2.3 .2$ & $.790^{-1}$ & 0,000 & Valid & & \\
\hline & $\times 2.4 .1$ & $.703^{-}$ & 0,000 & Valid & & \\
\hline & $\times 2.4 .2$ & $755^{\circ}$ & 0,000 & Valid & & \\
\hline & $\times 2.5 .1$ &, $754^{*}$ & 0,000 & Valid & & \\
\hline & $\times 2.5 .2$ & $.724^{-*}$ & 0,000 & Valid & & \\
\hline & $\times 2.6 .1$ & $809^{-}$ & 0.000 & Valid & & \\
\hline & $\times 2.6 .2$ & $.757^{*}$ & 0,000 & Valid & & \\
\hline \multirow{6}{*}{ Kompensasi $\left(x_{3}\right)$} & $\times 3.1 .1$ & $.727^{\prime \prime}$ & 0.000 & Valid & \multirow{6}{*}{0,839} & \multirow{6}{*}{ Reliabel } \\
\hline & $\times 3.1 .2$ & $763^{*}$ & 0.000 & Valid & & \\
\hline & $\times 3.1 .3$ & $.715^{\circ}$ & 0,000 & Valid & & \\
\hline & $\times 3.2 .1$ & $.735^{\circ}$ & 0.000 & Valid & & \\
\hline & $\times 3.3 .1$ & $718^{*}$ & 0.000 & Valid & & \\
\hline & $\times 3.3 .2$ & $.798^{-1}$ & 0,000 & Valid & & \\
\hline \multirow{12}{*}{ Motivasi Kerja ( $($ ) } & $\gamma-1$ & $.727^{\prime \prime}$ & 0,000 & Valid & \multirow{12}{*}{0,921} & \multirow{12}{*}{ Reliabel } \\
\hline & $Y: 2$ & $706^{*}$ & 0,000 & Valid & & \\
\hline & $\curlyvee .3$ &, $718^{*}$ & 0,000 & Valid & & \\
\hline & $Y .4$ & $.737^{*}$ & 0.000 & Valid & & \\
\hline & Y.5 & $.708^{*}$ & 0,000 & Valid & & \\
\hline & $Y .6$ & $.758^{*}$ & 0,000 & Vatid & & \\
\hline & $Y .7$ & $.724^{*}$ & 0.000 & Valid & & \\
\hline & $\gamma .8$ & $.789^{\circ}$ & 0.000 & Valid & & \\
\hline & Y.9 &, $728^{*}$ & 0,000 & Valid & & \\
\hline & $\gamma .10$ & $.727^{\circ}$ & 0,000 & Valid & & \\
\hline & $Y .11$ & .736 & 0,000 & Valid & & \\
\hline & $Y .12$ & .722 & 0,000 & Valid & & \\
\hline
\end{tabular}


Dijelaskan setiap pertanyaan dinyatakan valid dimana $r_{h i} \quad \geq r_{t}$. Sehingga instrumen validitas terbukti layak untuk dilanjutkan analisis data.

Dijelaskan uji reliabilitas diketahui nilai setiap variabel lebih besar dari nilai minimum reliabilitas sebesar 0,6. Sehingga terbukti bahwa keseluruhan item kuisioner dari masing-masing variabel tersebut reliabel atau konsisten.

\section{Uji Asumsi Klasik}

Uji Normalitas

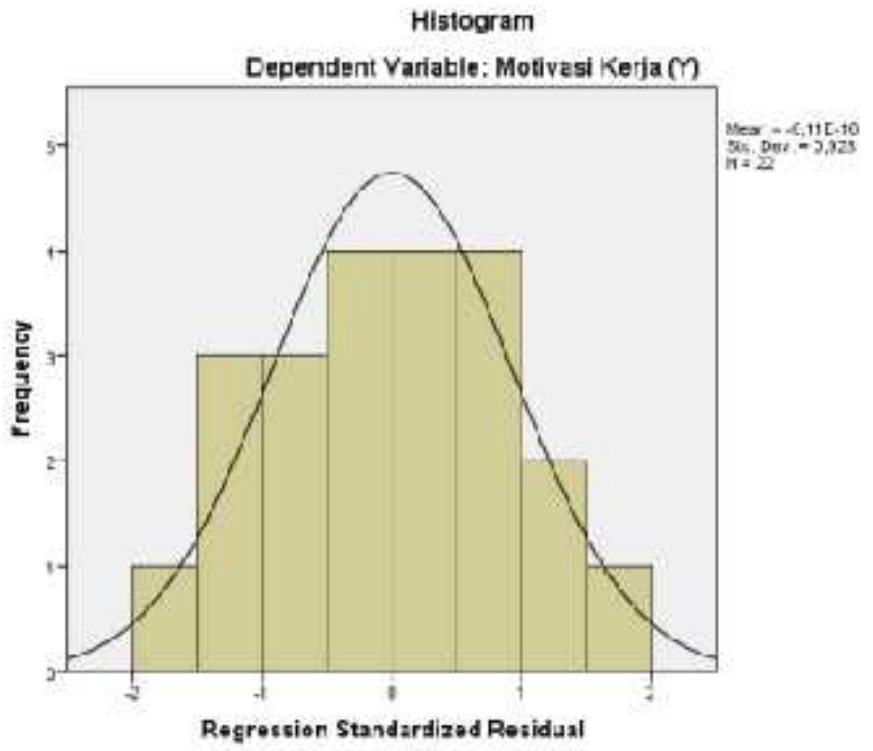

Gambar 2. Grafik Histogram

Dijelaskan pada kolmogorov-smirnov diperoleh nilai sig. 0,200 yang dapat dinyatakan regresi memenuhi asumsi normalitas. sehingga layak lanjut ke tahap selanjutnya.

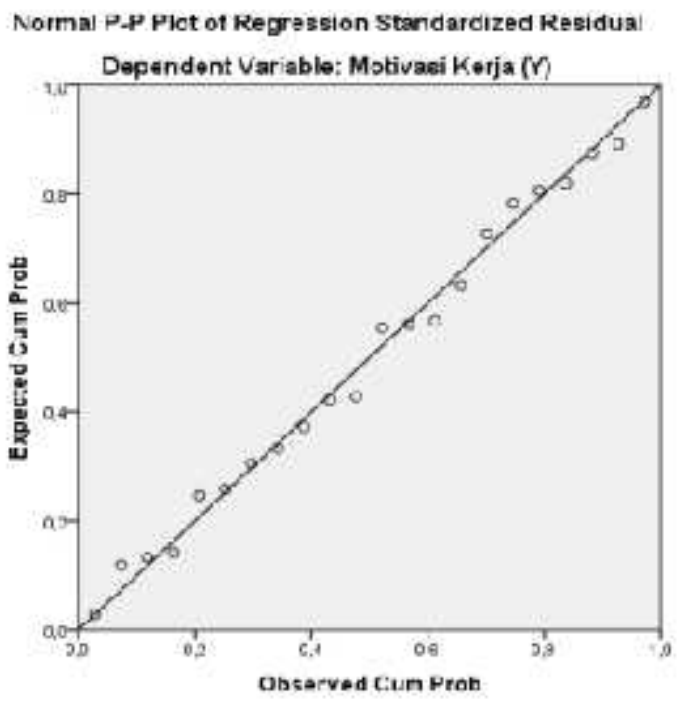

Gambar 3. Normal probability plot 
Dijelaskan grafik histogram berbentuk simetris tidak melenceng ke kanan maupun ke kiri sehingga model regresi memenuhi asumsi normalitass. Sehingga terbukti regresi berdristribusi normal.

Uji Multikolonieritas

Tabel 2. Uji Multikolonieritas

\begin{tabular}{ll|r|r} 
Model & \multicolumn{2}{|c}{$\begin{array}{c}\text { Collinearity Statistics } \\
\text { Tolerance }\end{array}$} \\
\hline 1 & (Constant) & 0,782 & 1,279 \\
\cline { 2 - 3 } & $\begin{array}{l}\text { Gaya Kepemimpinan } \\
(X 1)\end{array}$ & 0,688 & 1,454 \\
\cline { 2 - 3 } & Lingkungan Kerja (X2) & 0,860 & 1,163 \\
\hline
\end{tabular}

Dijelaskan uji multikolonieritas diperoleh VIF gaya kepemimpinan sebesar 1,279 < 10, nilai VIF pada variabel Lingkungan kerja sebesar 1,454 < 10, dan nilai VIF pada variabel kompensasi sebesar 1,163 $<10$. Berdasarkan hasil uji multikolonieritas tersebut dapat diputuskan bahwa hasil yang digunakan dalam penelitian ini bebas multikolonieritas, sehingga layak untuk diuji regresi.

\section{Uji Heteroskedastisitas}

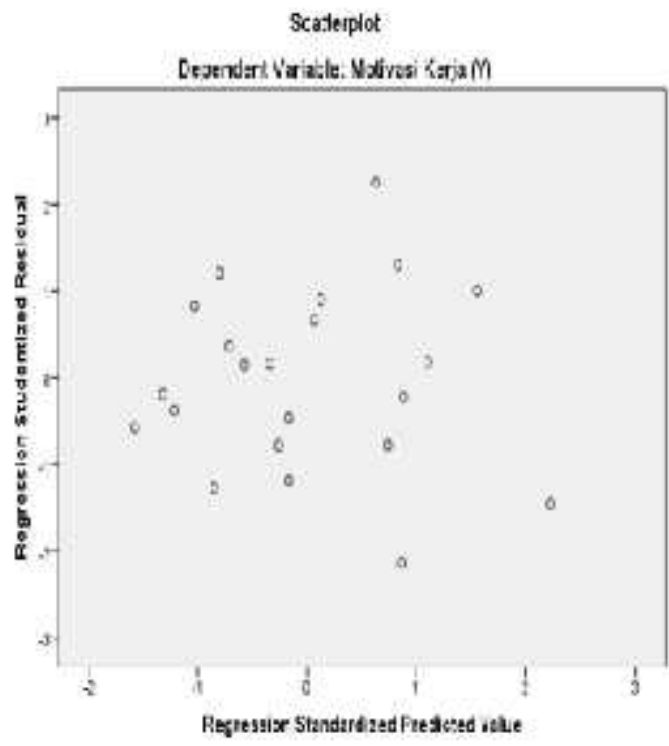

Gambar 4. Uji Heteroskedatisitas

Dijelaskan grafik scatterplot menunjukan acak di atas maupun di bawah angka 0 pada sumbu $Y$.

Uji Autokorelasi

Tabel 3. Autokorelasi

Model Summary ${ }^{\mathrm{b}}$

\begin{tabular}{ll|r|r|r|r} 
Model & R & R Square & $\begin{array}{c}\text { Adjusted R } \\
\text { Square }\end{array}$ & $\begin{array}{c}\text { Std. Error of } \\
\text { the Estimate }\end{array}$ & $\begin{array}{c}\text { Durbin- } \\
\text { Watson }\end{array}$ \\
\hline 1 &, $836^{\text {a }}$ & 0,698 & 0,648 & 2,921 & 1,704 \\
\hline
\end{tabular}


Dijelaskan nilai DW sebesar 1,704 dengan jumlah variabel bebas $(k)=2$, sampel $(n)=22$ dan $\mathrm{dl}=1,0529 \mathrm{du}=1,6640$. Maka $\mathrm{du}<\mathrm{dw}<4$-du yakni 1,6640 $<1,704<2,336$, sehingga dapat Terbukti hasil tersebut tidak terdapat autokorelasi sehingga layak dilakukan uji regresi.

\section{Pembahasan}

Dijelaskan hasil data diatas dikemukakan pembahasan berikut ini:

Berdasarkan uji statistik terbukti bahwa kompensasi tidak berpengaruh signifikan terhadap motivasi kerja. Pada variabel kompensasi tidak berpengaruh terhadap motivasi kerja dikarenakan pada hasil analisis uji-t menunjukkan nilai yang lebih besar dari 0,05 yang artinya Ho diterima dan Ha ditolak. Hal ini berarti menunjukkan bahwa kompensasi yang diperoleh pegawai penyandang disabilitas di Galeri Batik Wistara Surabaya tidak mempengaruhi motivasi kerja. Karena pada variabel kompensasi tersebut meliputi upah dan gaji, insentif, dan tunjangan. Kompensasi merupakan segala sesuatu yang pasti telah didapat oleh pegawai sehingga dapat mempengaruhi dirinya dalam melaksanakan pekerjaan yang telah diberikan.

Kemudian,. Apabila gaya kepemimpinan tidak dilakukan dengan benar atau sesuai dengan ketentuan yang ada, maka akan menimbulkan ketidaknyamanan maupun ketidaksesuaian dengan harapan pegawai sehingga dapat menurunkan motivasi kerja mereka. Dimana motivasi kerja dipandang positif oleh pegawai dalam melakukan pekerjaannya. Dalam hal ini berarti semakin baik pelaksanaan gaya kepemimpinan dan lingkungan kerja yang nyaman yang diperoleh pegawai, maka motivasi kerja yang dirasakan pegawai juga akan semakin meningkat.

Dalam hal ini lingkungan kerja juga perlu dinilai untuk mengetahui seberapa besar pegawai tersebut merasa nyaman dalam melakukan pekerjaannya. Selain itu, lingkungan kerja dalam penelitian ini sebagai salah satu kriteria penilaian dari segi tingkat kenyamanan pegawai untuk melaksanakan tanggung jawab dalam pekerjaan sehingga dapat menciptakan motivasi kerja pegawai menjadi meningkat.

Lingkungan kerja merupakan faktor vital penentu keterkendalian kondisi yang ada di lapangan, hal ini menjadi prioritas perusahaan dalam mengkondusifkan suasana yang aman terkendali, sebagai perusahaan dengan karyawan memiliki keterbatasan sudah sewajarnya lebih intens dan detail memperhatikan kondisi yang ada. Tanggung jawab manajemen menjamin keberadaan pegawai memiliki keterbatasan sangat dibutuhkan. Sehingga kesinambungan antara pegawai serta manajemen bisa terkoordiniasi dengan baik untuk mencapai tujuan perusahaan bersama.

\section{SIMPULAN}

Dijelaskan secara detail data sebelumnya, Dapat diperoleh simpulan berikut:

1. Uji hipotesis ditemukan adanya pengerauh gaya kepemimpinan secara signifikan terhadap motivasi kerja pegawai penyandang disabilitas di Galeri Batik Wistara Surabaya. Karena gaya kepemimpinan sangat diperlukan untuk pegawai penyandang disabilitas agar termotivasi dalam bekerja.

2. Uji hipotesis dibuktikan adanya pengaruh lingkungan kerja secara signifikan terhadap motivasi kerja pegawai penyandang disabilitas di Galeri Batik Wistara Surabaya. Karena suasana lingkungan kerja yang baik akan berpengaruh untuk kenyamanan kerja pegawai disabilitas.

3. Uji hipotesis terbukti adanya pengaruh kompensasi tidak signifikan terhadap motivasi kerja pegawai penyandang disabilitas di Galeri Batik Wistara Surabaya.

\section{IMPLIKASI}

Dalam meningkatkan semangat motivas kerja pegawai disabilitas diperoleh penelitian ini bergantung pada berbagai model variabel yang bervariasi dibidang sumber daya manusia. Banyak aspek bisa lebih di optimalkan dari pegawai disabilitas agar terus produktif. Ini juga dapat mendorong para pegawai penyandang disabilitas dalam meningkatkan kualitas kerja mereka. 


\section{KETERBATASAN PENELITIAN}

Dijelaskan keterbatasan antara lain:

1. Keterbatasan peneliti menjelaskan prosedur pengisian kuisioner terhadap pegawai penyandang disabilitas sehingga memerlukan bantuan dari pihak pemilik usaha.

\section{DAFTAR PUSTAKA}

Do Rêgo, Elvino Bonaparte dan Wayan Gede Supartha dan Ni Nyoman Kerti Yasa, 2017, Pengaruh Kepemimpinan Terhadap Motivasi dan Kinerja Karyawan pada Direktorat Jendral Administrasi dn Keuangan, Kementerian Estatal Timor Leste, E-Jurnal Ekonomi dan Bisnis, ISSN 2337-3067, hal 3731-3764, Universitas Udayana Denpasar Bali.

Efendi, Arief Burhan dan Rahaditya Yunianto. 2017. Implementasi Diversity Program Bagi Tenaga Kerja Penyandang Disabilitas Pada PT. Wangta Agung Kota Surabaya. Indonesia Journal Of Disability Studies (IJDS) 2017, Vol. 04, No.02, ISSN: 2355-2158, hal. 96-103, Universitas Brawijaya.

Fauzi, 2017, Pengaruh Kompensasi dan Lingkungan Kerja Terhadap Kepuasan Kerja PT. Tor Ganda Medan, Jurnal Riset Manajemen dan Bisnis (JRMB), Vol. 2, No. 3, hal 36-47, Universitas Islam Sumatera Utara.

Haryani, Sagita Sukma dan Djamhur Hamid dan Heru Susilo, 2015, Pengaruh kompensasi Terhadap Motivasi Kerja dan Kinerja (Studi Pada Karyawan PT. Telekomunikasi Indonesia, Tbk. Malang, Jurnal Administrasi Bisnis (JAB), vol. 25, No. 1, hal 1-7,Universitas Brawijaya Malang.

Hidayat, Yayat Rahmad dan Nopika Aryanti, 2016, Pengaruh Kompensasi Dan Motivasi Kerja Terhadap Kinerja Karyawan (Studi Kasus Pada Pabrik Bawang Goreng" Ud. Sinar Tani" Di Desa Pagundan Kecamatan Lebak Wangi Kabupaten Kuningan). Jurnal Agrinis, Vol. 1, No. 1, hal 57-74, Universitas Swadaya Gunung Jati.

Johannes, Andrew C. dan Adolfina dan Rita N. Taroreh, 2016, Pengaruh Gaya Kepemimpinan, Kompensasi, dan Lingkungan Kerja Terhadap Kinerja Agen Pada AJB Bumiputera 1912 Cabang Tikala, Jurnal Berkala Ilmiah efisiensi, Vol. 16, No. 01, hal 53-63, Universitas Sam Ratulangi Manado. Mandey, Maya Agustin dan Victor P.K. Lengkong, 2015, Pengaruh Kompensasi, Gaya Kepemimpinan, dan Lingkungan Kerja Terhadap Kinerja Pegawai (Studi Pada Fakultas Ekonomi dan Bisnis Universitas Sam Ratulangi Manado), Jurnal Bisnis, ISSN: 2303-11, Vol. 3, No. 3, hal. 1383-1394, Universitas Sam Ratulangi Manado.

Masyhuri dan Zainuddin, 2008. Metodologi Penelitian Pendekatan Praktis dan Aplikatif. Bandung: PT. Refika Aditama.

Pratama, Yosef Ferry dan Dian Wismar'ein, 2018, Pengaruh Pelatihan dan Lingkungan Kerja Karyawan, Business Management Analysis Journal (BMAJ), ISSN 2623-0690, Vol. 1, No. 1, hal 26-36, Universitas Muria Kudus. 